\title{
Immunogenicity of a Recombinant Influenza Virus Bearing Both the CD4+ and CD8+ T Cell Epitopes of Ovalbumin
}

\author{
Bruno Garulli, ${ }^{1,2}$ Giuseppina Di Mario, ${ }^{1}$ Ester Sciaraffia, ${ }^{1}$ Yoshihiro Kawaoka, ${ }^{3,4,5}$ \\ and Maria R. Castrucci ${ }^{1}$ \\ ${ }^{1}$ Department of Infectious, Parasitic and Immune-Mediated Diseases, Istituto Superiore di Sanità, 00161 Rome, Italy \\ ${ }^{2}$ Department of Biology and Biotechnology "Charles Darwin", University of Rome "La Sapienza", 00185 Rome, Italy \\ ${ }^{3}$ Department of Pathobiological Sciences, School of Veterinary Medicine, University of Wisconsin-Madison, WI 53706, USA \\ ${ }^{4}$ Division of Virology, Department of Microbiology and Immunology, and International Research Center for Infectious Diseases, \\ Institute of Medical Science, University of Tokyo, Shirokanedai, Minato-ku, Tokyo 108-8639, Japan \\ ${ }^{5}$ ERATO Infection-Induced Host Responses Project, Japan Science and Technology Agency, Saitama 332-0012, Japan
}

Correspondence should be addressed to Maria R. Castrucci, mariarita.castrucci@iss.it

Received 28 June 2011; Revised 5 August 2011; Accepted 10 August 2011

Academic Editor: Zhengguo Xiao

Copyright (c) 2011 Bruno Garulli et al. This is an open access article distributed under the Creative Commons Attribution License, which permits unrestricted use, distribution, and reproduction in any medium, provided the original work is properly cited.

\begin{abstract}
Recombinant influenza viruses that bear the single immunodominant CD8+ T cell epitope $\mathrm{OVA}_{257-264}$ or the CD4+ T cell epitope $\mathrm{OVA}_{323-339}$ of the model antigen ovalbumin (OVA) have been useful tools in immunology. Here, we generated a recombinant influenza virus, $\mathrm{WSN}_{-} \mathrm{OVA}_{\mathrm{I} / \mathrm{II}}$, that bears both OVA-specific CD8+ and CD4+ epitopes on its hemagglutinin molecule. Live and heat-inactivated WSN-OVA $/$ /II viruses were efficiently presented by dendritic cells in vitro to OT-I TCR transgenic CD8+ T cells and OT-II TCR transgenic CD4+ T cells. In vivo, WSN-OVA $\mathrm{I}_{/ I I}$ virus was attenuated in virulence, highly immunogenic, and protected mice from B16-OVA tumor challenge in a prophylactic model of vaccination. Thus, WSN-OVA $\mathrm{I} / \mathrm{II}$ virus represents an additional tool, along with OVA TCR transgenic mice, for further studies on T cell responses and may be of value in vaccine design.
\end{abstract}

\section{Introduction}

Recombinant influenza viruses represent a promising delivery system of foreign antigens that can be fused to viral proteins, such as hemagglutinin (HA), neuraminidase (NA), or nonstructural protein 1 (NS1), or can be expressed as an individual whole protein flanked with NA segmentspecific packaging signals [1-5]. Influenza viruses bearing model antigens have been used as tools to address several questions and long-standing issues in immune biology. In particular, recombinant influenza viruses bearing the single immunodominant $\mathrm{CD} 8+\mathrm{T}$ cell epitope $\mathrm{OVA}_{257-264}$ or the CD4+ T cell epitope $\mathrm{OVA}_{323-339}$ of chicken ovalbumin (OVA) have been used in several studies to characterize $\mathrm{T}$ cell responses [6-12].

HA engineered to carry small polypeptides fused to its $\mathrm{N}$ terminus is efficiently expressed and stably incorporated into retroviral particles without affecting its fusion activity [13].
Recently, this strategy was adopted to generate recombinant influenza viruses bearing relatively large domains of the protective antigens of Bacillus anthracis toxin (domain 1', the region responsible for binding to the lethal factor and the edema factor (LEF) and domain 4, the receptorbinding domain (RBD)) fused to the $\mathrm{N}$-terminus of the $\mathrm{HA}$ of A/Aichi/2/68 (H3N2) in the genetic background of A/WSN/33 virus (H1N1) [14, 15]. The chimeric fusion proteins, named $\mathrm{HA} / \mathrm{LEF}$ and $\mathrm{HA} / \mathrm{RBD}$, were functionally expressed during virus infection in mice and elicited antibody responses specific to both the viral HA and the protein domains of the Bacillus anthracis toxin. Here, by using a similar approach, we generated a recombinant influenza virus, $\mathrm{WSN}^{-O V A} \mathrm{I}_{\mathrm{III}}$, bearing both OVA-specific CD8+ and CD4+ epitopes in its HA, and characterized the OVA-specific T cell immune response in vitro and in vivo as well as its ability to protect mice from challenge with the OVA-expressing tumor cells B16-OVA in a prophylactic model of vaccination. 


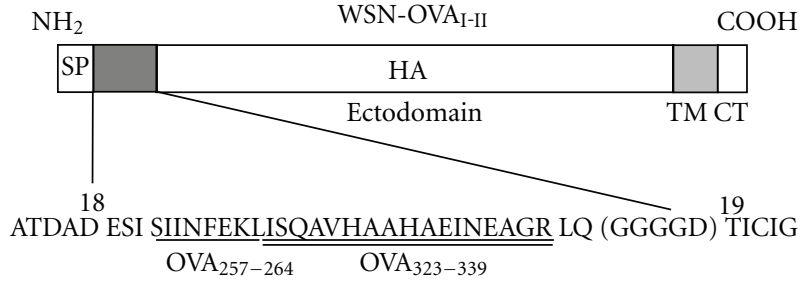

FIGURE 1: Construction of the mutant hemagglutin in (HA) segment. Schematic representation of the $\mathrm{HA} / \mathrm{OVA}_{\mathrm{I} / \mathrm{II}}$ construct, containing the OVA epitopes inserted after the HA signal peptide (SP). CT, $\mathrm{TM}=$ cytoplasmic, transmembrane domains of HA, respectively.

\section{Materials and Methods}

2.1. Mice. Female C57BL/6J mice and the TCR-transgenic mouse line OT-II, expressing a TCR that recognize the $\mathrm{OVA}_{323-339}$ epitope, were obtained from Charles River, Calco, Italy. The TCR-transgenic mouse line OT-I, expressing a TCR that recognize an $\mathrm{H}-2^{\mathrm{b}}$-restricted $\mathrm{OVA}_{257-264}$ epitope, SIINFEKL, was kindly supplied by Dr. M. Bellone (San Raffaele Scientific Institute, Milan, Italy). For all experiments, mice, aged 6-12 weeks, were maintained at the Istituto Superiore di Sanità by following institutional guidelines and approved protocols.

2.2. Generation of Recombinant WSN-OVA $\mathrm{I} / \mathrm{II}$ Virus. The coding sequences for the $\mathrm{OVA}_{257-264}$ (SIINFEKL) and $\mathrm{OVA}_{323-339}$ (ISQAVHAAHAEINEAGR) T cell epitopes were inserted into the HA gene of A/WSN/33 virus, between the coding regions that correspond to the $\mathrm{C}$-terminus of the $\mathrm{HA}$ signal peptide (SP) and the N-terminus of the protein following signal peptidase cleavage. Specifically, a pair of complementary oligonucleotides encoding the OVA epitopes, designated $\mathrm{OVA}_{\mathrm{I} / \mathrm{II}}$, with flanking ClaI/PstI sites (encoding ESI and LQ amino acids, resp.) was inserted into the cloning cassette generated at the $3^{\prime}$ end of the signal peptide coding sequence of the pPolI-WSN HA plasmid [16], and containing the GGGGD peptide arm, as described by Li et al. [14] (Figure 1). The recombinant influenza WSN-OVA $\mathrm{I} / \mathrm{II}$ virus bearing both of the OVA-specific CD8+ and CD4+ epitopes was generated by use of plasmid-driven reverse genetics, as described by Neumann et al. [16]. The presence of the inserted sequence was confirmed by sequencing.

2.3. Antigen Presentation In Vitro. For the antigen presentation assays in vitro, CD8+ and CD4+ $\mathrm{T}$ cells were isolated from spleens and lymph nodes of OT-I and OT-II OVA TCR transgenic mice, respectively, by use of magnetic sorting (Miltenyi Biotec), according to the manufacturer's protocol. CD11c-positive dendritic cells (DCs) were isolated from the spleens of C57BL/6 mice by using MACS beads (Miltenyi Biotec) and the purity of the enriched CD11cpositive cell preparation ranged from $90 \%$ to $95 \%$. DCs were resuspended to $10^{7}$ cells $/ \mathrm{mL}$ in serum-free RPMI 1640, and incubated with either live or heat-inactivated (HI) WSN$\mathrm{OVA}_{\mathrm{I} / \mathrm{II}}$ virus $(1000 \mathrm{HAU} / \mathrm{mL})$ for $1 \mathrm{~h}$ at $37^{\circ} \mathrm{C}, 5 \% \mathrm{CO}_{2}$. Heat inactivation was performed by incubating WSN$\mathrm{OVA}_{\mathrm{I} / \mathrm{II}}$ virus at $56^{\circ} \mathrm{C}$ for $30 \mathrm{~min}$ in a water bath, and virus fusion activity and inactivation were determined as previously described [17]. After incubation, antigen-loaded DCs were washed and cultured with $10^{5}$ enriched OT-I or OT-II cells for $48 \mathrm{~h}$, after which $0.5 \mu \mathrm{Ci} /$ well $\left[{ }^{3} \mathrm{H}\right]$ thymidine (Amersham Biosciences, UK) was added for $16 \mathrm{~h}$ before harvesting. For the carboxyfluorescein succinimidyl ester(CFSE-) based lymphoproliferation assay, live virus-pulsed DCs were coincubated with $2 \times 10^{6}$ CFSE-labelled OTI or OT-II cells; $72 \mathrm{~h}$ later, the cells were stained with anti-CD8-phycoerythrin and anti-CD4-phycoerytrin (PE), respectively, for flow cytometry.

2.4. Experimental Infection. Five-week-old female C57BL/6J mice, anesthetized with Avertin given intraperitoneally, were inoculated intranasally (i.n.) with $50 \mu \mathrm{L}$ of $\mathrm{WSN}_{-} \mathrm{OVA} / \mathrm{II}$ virus at different dilutions (five mice per dilution) and observed for 21 days to determine the minimal dose lethal to $50 \%$ of mice $\left(\mathrm{MLD}_{50}\right)$. For virological analysis, mice were inoculated with $3 \times 10^{5} \mathrm{PFU}$ of $\mathrm{WSN}-\mathrm{OVA}_{\mathrm{I} / \mathrm{II}}$ virus or $5 \times$ $10^{2} \mathrm{PFU}$ of WSN virus, and virus titres in the lungs and nasal turbinates were determined 3 days and 6 days after infection by use of MDCK cells, as described previously [18].

2.5. Immunization and Tumor Challenge. Female C57BL/6J mice were i.n. immunized with $3 \times 10^{5} \mathrm{PFU}$ of WSN$\mathrm{OVA}_{\mathrm{I} / \mathrm{II}}$ virus or $5 \times 10^{2} \mathrm{PFU}$ of WSN virus. Nine days later, five mice from each group were sacrificed to obtain spleens and mediastinal lymph nodes (MLN), and epitopespecific $\mathrm{T}$ cell responses were determined by using a mouse IFN- $\gamma$ enzyme-linked immunospot assay (ELISPOT) kit (Pharmingen, BD). Specifically, a single-cell suspension from lymphoid tissues was cultured with either $\mathrm{OVA}_{257-264}$ or the viral nucleoprotein $\left(\mathrm{NP}_{366-374}\right)$ peptide, whereas enriched CD4+ T cells from the MLN were cultured for $48 \mathrm{~h}$ with the $\mathrm{OVA}_{323-339}$ peptide and irradiated (2.500 rads) naïve splenocytes. Tumor challenge experiments were carried out by injecting intravenously (i.v.) $3 \times 10^{5} \mathrm{~B} 16$-OVA cells into groups of mice that had been immunized three weeks earlier with WSN or WSN-OVA $\mathrm{I} / \mathrm{II}$ virus. Twelve days after tumor cell injection, eight mice from each group were sacrificed, and lung metastases were enumerated under a dissection microscope. Nonimmunized mice served as naïve controls. In addition, the frequency of SIINFEKL-specific IFN- $\gamma$ producing $\mathrm{T}$ cells was measured by using the ELISPOT assay on spleen-derived lymphocytes.

\section{Results}

The recombinant influenza WSN-OVA $\mathrm{III}_{\text {II }}$ virus bearing both the OVA-specific CD8+ and CD4+ epitopes was generated by introducing the coding sequences into the HA gene of A/WSN/33 virus, after the coding region of the HA signal peptide (SP), and the GGGGD peptide arm, as described by Li et al. [14] (Figure 1). The rescued virus replicated in tissue culture with a titer ranging from $5 \times 10^{6}$ to $10^{7}$ plaqueforming units (PFU)/mL.

We first determined whether the OVA-specific $\mathrm{T}$ cell epitopes of WSN-OVA to antigen-specific $\mathrm{T}$ cells. To this end, the capacity of 

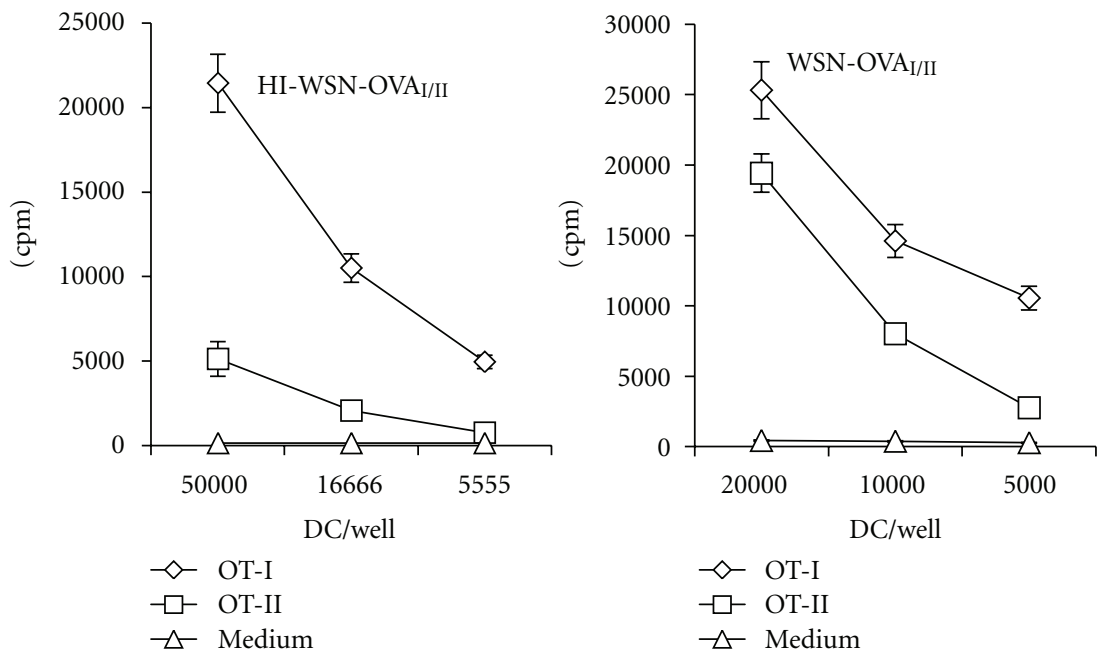

(a)

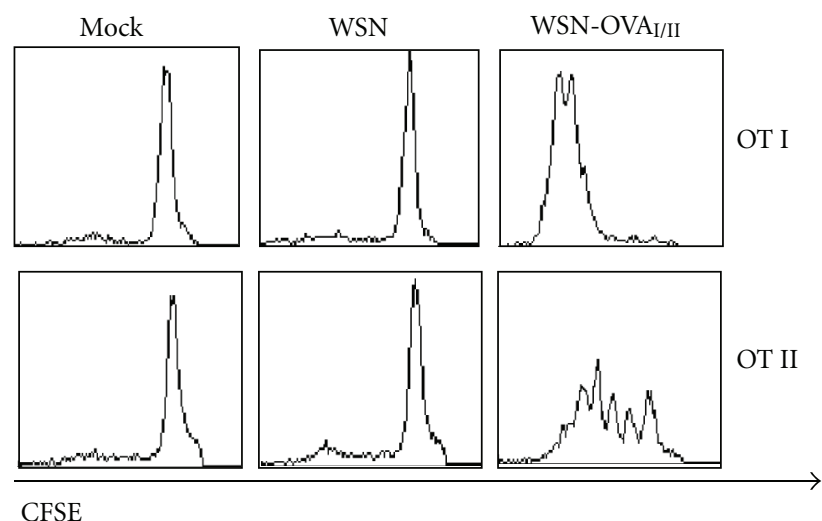

(b)

FIgURe 2: Presentation of WSN-OVA $\mathrm{I/I}$ virus by dendritic cells (DCs) in vitro to OVA-specific CD8+ and CD4+ T cells. (a) Splenic DCs were incubated with either live or heat-inactivated (HI) WSN-OVA $\mathrm{I}_{\mathrm{III}}$ virus and then washed and titrated in microtiter plates. OT-I cells and OT-II cells were added to the cultures $\left(10^{5} /\right.$ well $)$, and $\mathrm{T}$ cell proliferation was estimated by use of $\left[{ }^{3} \mathrm{H}\right]$ thymidine incorporation two days later. The data shown are the means $( \pm$ SEM) from triplicate cultures. (b) CFSE-labelled naïve OT-I and OT-II cells were coincubated with live virus-pulsed or control DCs. Three days later, proliferation of CD8+ and CD4+ T cells was determined by using flow cytometry. The results shown are representative of three experiments.

splenic DCs to process and present both live and HI WSN-OVA $_{\mathrm{I}-\mathrm{II}}$ viruses was assessed by using an in vitro proliferation assay of naïve OVA-specific $\mathrm{CD}^{+} \mathrm{T}$ and $\mathrm{CD} 4+$ T cells derived from OT-I and OT-II TCR-transgenic mice, respectively. Live virus-loaded DCs efficiently processed and presented both OVA-specific epitopes on MHC class I and II molecules, whereas there was no response with uninfected DCs (Figure 2(a)). CFSE-labelled transgenic T cells were also used to monitor antigen-specific proliferation due to the progressive halving of the dye fluorescence following cell division. WSN-OVAI/II virus-loaded DCs were responsible for vigorous proliferation of OT-I and OT-II cells within the $\mathrm{CD} 8+$ and $\mathrm{CD} 4+$ gated populations, respectively, compared to unloaded- or WSN virus-loaded DCs (Figure 2(b)). Furthermore, our data indicate that the OVA-specific MHC class I-restricted epitope located on the HA of whole HI
WSN-OVA $\mathrm{I} / \mathrm{II}$ virus was efficiently cross-presented by DCs to CD8+ T cells (Figure 2(a)). The binding and fusogenic functions of HI WSN-OVA $\mathrm{I} / \mathrm{II}$ virus were intact as assessed by standard hemagglutinating and hemolytic assays, respectively, thus confirming the importance of a functional HA to access the cytoplasm of DCs [17]. The higher T cell proliferation of OT-I compared to OT-II cells induced by DCs loaded with HI WSN-OVA $\mathrm{I}_{\text {/II }}$ virus, bearing equimolar amounts of both epitopes, correlates with previous data showing that the cell-associated antigen is more efficiently presented to CD8+ than to CD4+ T cells [19].

To determine the immunogenicity of the WSN-OVA $\mathrm{I}_{\mathrm{III}}$ virus in C57BL/6J mice, we first determined its pathogenicity relative to the wild-type WSN virus. None of the inoculated mice died, even those inoculated with doses of WSN$\mathrm{OVA}_{\mathrm{I} / \mathrm{II}}$ virus as high as $10^{6} \mathrm{PFU}$, whereas the wild-type 


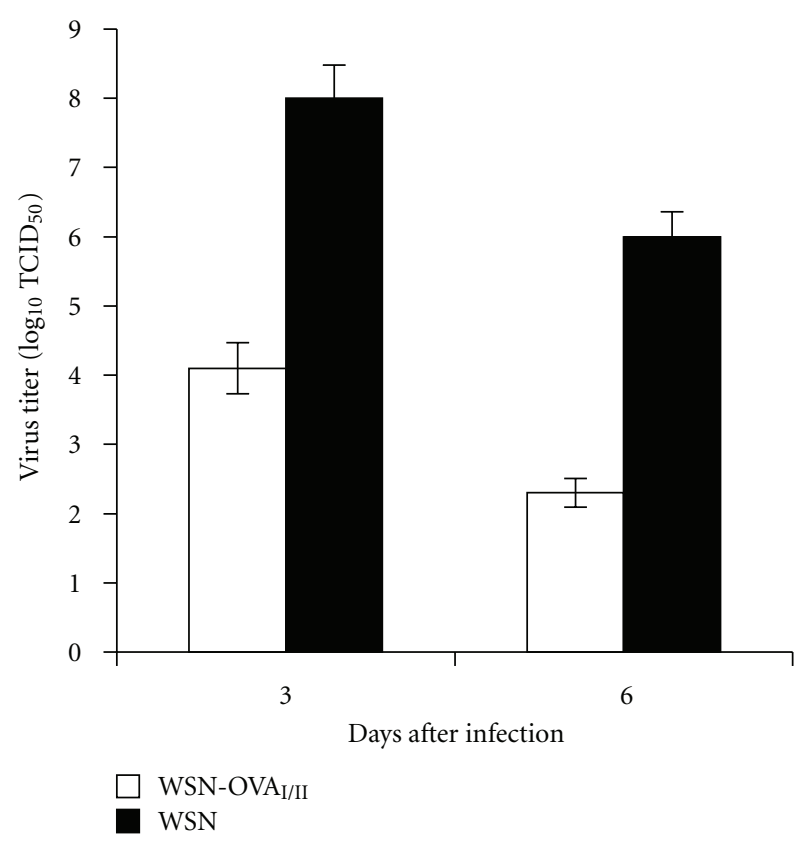

FIgUre 3: Replication of WSN-OVA $\mathrm{I} / \mathrm{II}$ virus in mice. C57BL/6 $\mathrm{J}$ mice were inoculated i.n. under anaesthesia with $5 \times 10^{2} \mathrm{PFU}$ of WSN virus or $3 \times 10^{5} \mathrm{PFU}$ of WSN-OVA $\mathrm{I} / \mathrm{II}$ virus, and sacrificed on days 3 and 6 after infection for virus titration in lungs on MDCK cells. The values presented are averages of triplicate wells; the error bars indicate the standard deviation.

WSN virus killed all of the mice at this dose (data not shown). Pulmonary viral loads measured 3 and 6 days after infection in mice inoculated with $3 \times 10^{5} \mathrm{PFU}$ of WSN$\mathrm{OVA}_{\mathrm{I} / \mathrm{II}}$ virus (average titres of 4.1 and $2.3 \log _{10} \mathrm{TCID}_{50} /$ lung, resp.) were about four logs lower than those observed for mice inoculated with $5 \times 10^{2} \mathrm{PFU}$ of the wild-type WSN virus (Figure 3 ). Moreover, we could not detect virus in the nasal turbinates of the WSN-OVA $\mathrm{I} / \mathrm{II}$-infected mice, whereas detectable viral titres were measured in the nasal turbinates of the WSN-infected animals on day 3 and 6 after infection (data not shown). Although the recombinant virus did not replicate as efficiently as the WSN virus, we used the above viral doses to immunize mice and measured comparably high levels of NP-specific CD8+ T cells for both viruses in the MLN and in the spleen at day 9 after infection (Figure 4(a)). The OVA-specific CD8+ T cell response was also vigorous, as determined by ex vivo IFN- $\gamma$ release by lymphoid cells after the addition of specific peptides (Figure 4(a)) indicating that the attenuated recombinant virus was efficiently immunogenic for $\mathrm{CD} 8+\mathrm{T}$ cells. To assess whether the engineered OVA-specific CD4+ T cell epitope was also presented in the context of infection, we measured the $\mathrm{OVA}_{323-339}$-specific CD4+ T cells secreting IFN- $\gamma$ in the enriched CD4+ T cell population from the MLN of these mice. WSN-OVA $\mathrm{I}_{\mathrm{I} I \mathrm{I}}$-infected mice produced an average of 120 spot-forming cells (SFC)/million cells, whereas WSNinfected mice gave no OVA-specific response (Figure 4(b)). Although the insertion of foreign epitopes into the HA of WSN-OVA $\mathrm{I} / \mathrm{II}$ virus was responsible for the attenuated phenotype, the double OVA recombinant virus was still replicating and inducing a remarkable OVA-specific $\mathrm{T}$ cell response in mice.

Recombinant viral vectors expressing the immunodominant OVA-specific CD8+ T cell epitope induce protective immunity against challenge with lethal doses of malignant melanoma cells expressing OVA [20, 21]. Moreover, recombinant influenza viruses expressing a tumor-associated antigen have been previously shown to elicit efficient antitumor responses and to induce tumor inhibition in experimental murine cancer models [22, 23]. We, therefore, examined the ability of WSN-OVA $1 /$ II virus to protect mice against tumors by using the tumor cell line B16-OVA (OVA-transfected B16 cells), which cause pulmonary metastases when given intra-

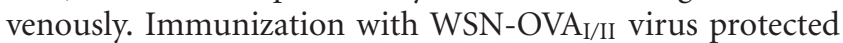
mice from lung metastases, as measured 12 days after tumor challenge, compared to nonimmunized mice (Figure 5(a)). The antitumor immunity was OVA-specific, as all of the mice immunized with the parental WSN virus developed tumors. We also found that WSN-OVA $\mathrm{I}_{\mathrm{I} / \mathrm{II}}$ virus-immunized mice produced a stronger $\mathrm{OVA}_{257-264}$ (SIINFEKL-)specific CD8+ $\mathrm{T}$ cell response than did either the nonimmunized mice or the wild-type WSN virus-immunized mice, as measured by ex vivo ELISPOT with pooled spleens on day 12 posttumor challenge (Figure 5(b)). The higher $\mathrm{OVA}_{257-264^{-}}$ specific CD8+ $\mathrm{T}$ cell response detected in $\mathrm{WSN}^{-O V A_{\mathrm{I} / \mathrm{II}}}$ virus-immunized mice that were subsequently challenged with B16-OVA cells correlated with the presence of OVAspecific memory $\mathrm{T}$ cells in these mice before tumor challenge.

\section{Discussion}

Here, we engineered a recombinant influenza WSN-OVA $\mathrm{I}_{\mathrm{III}}$ virus to bear the OVA-specific CD4+ and CD8+ T cell epitopes on its viral HA. This virus showed an attenuated phenotype and was highly immunogenic in mice. The effective proliferation of OVA-specific CD8 $+\mathrm{T}$ cells in vitro with $\mathrm{HI}$ WSN-OVA $\mathrm{I} / \mathrm{II}$ virus-loaded DCs is in agreement with previous data showing that inactivated influenza viruses that maintain their fusogenic properties are efficiently crosspresented by DCs [17]. The presence of both OVA T cell epitopes on the same viral HA protein provides an additional tool, along with OVA-specific TCR transgenic mice, to investigate antigen processing and presentation by nonreplicating influenza virus-loaded DCs, in the context of MHC class I and class II. The double OVA recombinant virus thus represents an attractive delivery system for use in studies that explore new vaccination strategies for inducing virus-specific memory CD8+ T cells. Moreover, the finding that foreign epitopes located on the HA of inactivated recombinant influenza virions are efficiently cross-presented to specific CD8+ $\mathrm{T}$ cells offers interesting opportunities to further explore the use of recombinant influenza virusbased nonreplicating immunogens. In particular, this feature could be used to develop virosomes, as antigen delivery systems, since antigen encapsulation inside the virosomal particles is usually required for cytosolic delivery upon membrane fusion and for proteasome processing to induce CTL responses [24]. 

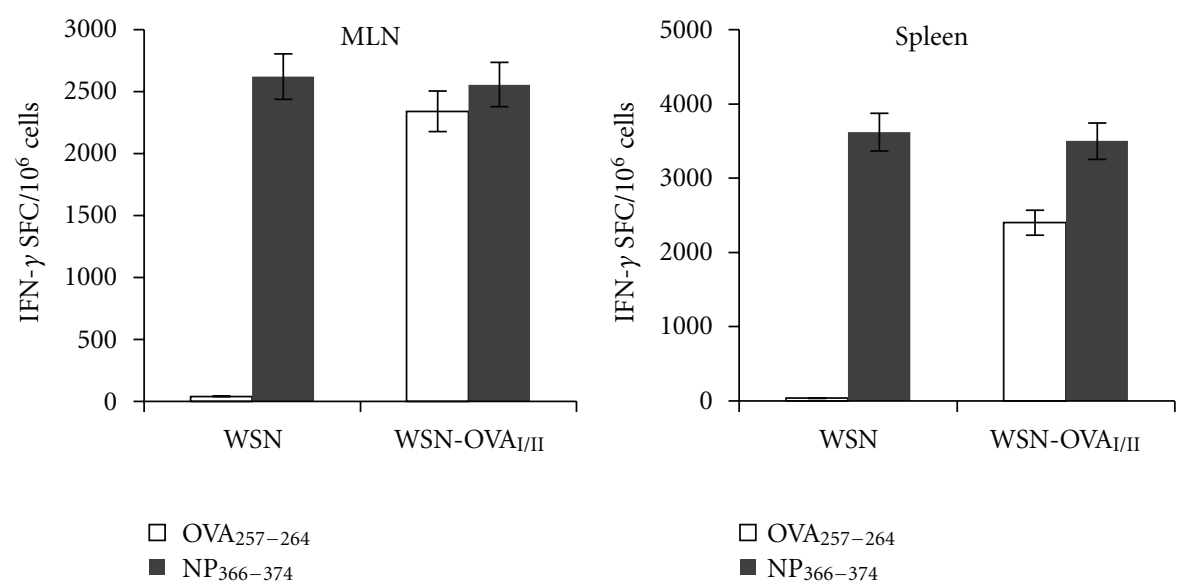

(a)

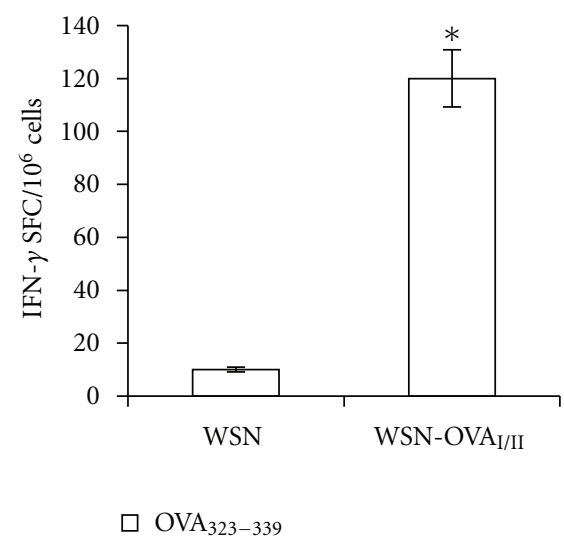

(b)

FIgURE 4: T cell responses in WSN-OVA $\mathrm{I}_{\mathrm{III}}$ virus-infected mice. C57BL/6J mice were immunized i.n. with $5 \times 10^{2} \mathrm{PFU}$ of WSN virus or $3 \times 10^{5} \mathrm{PFU}$ of $\mathrm{WSN}^{-O V A_{\mathrm{I} / \mathrm{II}}}$ virus, and sacrificed on day 9 for measuring epitope-specific CD8+ T cell responses in mediastinal lymph nodes (MLN) and spleens (a) and CD4+ T cell responses in MLN (b), respectively, by use of an IFN- $\gamma$ ELISPOT assay with the indicated peptides. The values presented are averages of triplicate wells; the error bars indicate the standard deviation. The data are representative of three experiments. ${ }^{*} P<0.05$ comparing WSN- versus WSN-OVA $\mathrm{I}_{\mathrm{I} / \mathrm{II}}$-infected mice.

Our results also show that immunization with WSN$\mathrm{OVA}_{\mathrm{I} / \mathrm{II}}$ virus protects mice from B16-OVA tumor challenge. Here, we did not directly address the question of whether the double OVA recombinant virus has advantages over the existing recombinant viruses that bear the single OVA epitopes. Although the induction of $\mathrm{OVA}_{257-264}$ (SIINFEKL-)specific CD8+ T cells in the context of viral infection may be sufficient to provide protective immunity, it is plausible that the simultaneous induction of tumorspecific CD4+ $\mathrm{T}$ cells may participate in interactions that shape the protective response against tumors [21]. This is particularly true if tumor-specific immune responses are induced with nonreplicating immunogens and thus in the presence of a poor inflammatory response. Recent studies suggest that abnormalities of the immune response in tumor-bearing hosts correlate with the induction of immune tolerance toward tumor-associated antigens and with the functional suppression of antitumor $\mathrm{T}$ cell effectors due to myeloid-derived suppressor cells $[25,26]$. Thus, combining $\mathrm{WSN} \mathrm{OVA}_{\mathrm{I} / \mathrm{II}}$ virus infection and adoptive transfer of OVAspecific TCR transgenic $T$ cells in mice bearing OVAexpressing tumors may help dissect the immunoregulatory mechanisms responsible for tumor-induced tolerance and immune suppression and may provide useful information for rational design of cancer immunotherapy.

\section{Acknowledgments}

The authors thank Andrea Giovannelli for assistance with the animal experiments, Sabrina Tocchio and Roberto Gilardi for help with the paper, and Susan Watson for scientific editing. This work was funded by the European Union's Seventh Framework Programme under Grant Agreement no. 201169 (Identification of Mechanisms Correlating with 


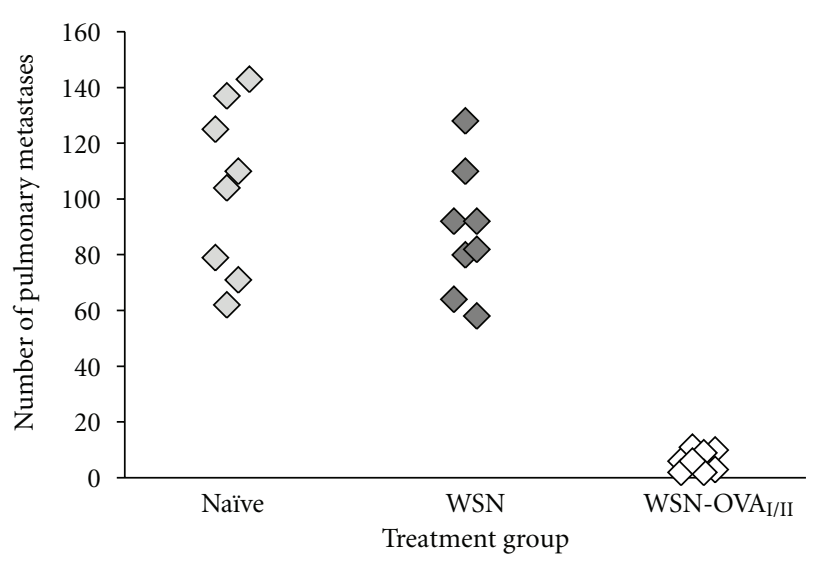

(a)

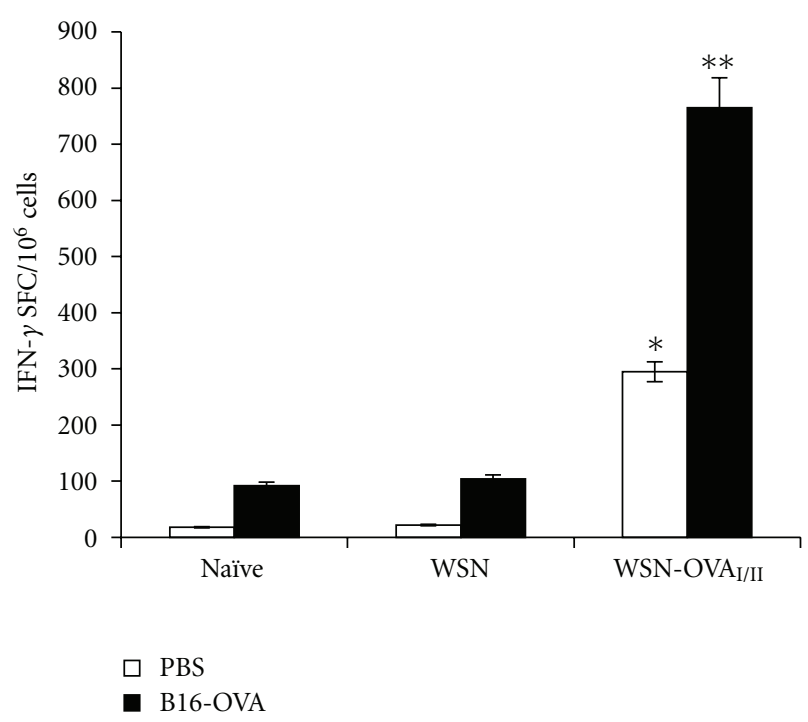

(b)

Figure 5: Protective and antigen-specific immunity to melanoma B16 cells expressing OVA. C57BL/6J mice were immunized once with either the parental WSN virus or the recombinant WSN$\mathrm{OVA}_{\mathrm{I} / \mathrm{II}}$ virus. Three weeks after immunization, mice were challenged i.v. with $3 \times 10^{5} \mathrm{~B} 16$-OVA cells or with PBS. The number of pulmonary metastases (a) and the frequency of SIINFEKL-specific IFN- $\gamma$-producing T cells, as measured by using the ELISPOT assay on spleen-derived lymphocytes (b) was determined 12 days after the tumor cell inoculation. All of the experiments included 8 mice per group and were repeated three times with similar results. ${ }^{*} P<0.001$ and ${ }^{* *} P<0.0001$, comparing WSN-OVA $\mathrm{I}_{\mathrm{I} / \mathrm{II}}$-versus WSN-infected and naïve mice.

Susceptibility for Avian Influenza, IMECS). The study was also funded by ERATO (Japan Science and Technology Agency), by a grant-in-aid for Specially Promoted Research from the Ministries of Education, Culture, Sports, Science, and Technology, by grants-in-aid from Health, Labor, and Welfare of Japan, and by National Institute of Allergy and Infectious Disease Public Health Service research grants.

\section{References}

[1] A. García-Sastre, "Transfectant influenza viruses as antigen delivery vectors," Advances in Virus Research, vol. 55, pp. 579$597,2000$.

[2] B. Ferko, J. Stasakova, S. Sereinig et al., "Hyperattenuated recombinant influenza A virus nonstructural-protein-encoding vectors induce human immunodeficiency virus type $1 \mathrm{Nef}-$ specific systemic and mucosal immune responses in mice," Journal of Virology, vol. 75, no. 19, pp. 8899-8908, 2001.

[3] A. V. Machado, N. Naffakh, S. van der Werf, and N. Escriou, "Expression of a foreign gene by stable recombinant influenza viruses harboring a dicistronic genomic segment with an internal promoter," Virology, vol. 313, no. 1, pp. 235-249, 2003.

[4] K. Shinya, Y. Fujii, H. Ito, T. Ito, and Y. Kawaoka, "Characterization of a neuraminidase-deficient influenza A virus as a potential gene delivery vector and a live vaccine," Journal of Virology, vol. 78, no. 6, pp. 3083-3088, 2004.

[5] Q. Gao, A. C. Lowen, T. T. Wang, and P. Palese, "A ninesegment influenza A virus carrying subtype $\mathrm{H} 1$ and $\mathrm{H} 3$ hemagglutinins," Journal of Virology, vol. 84, no. 16, pp. 80628071, 2010.

[6] B. J. G. Baaten, C. R. Li, M. F. Deiro, M. M. Lin, P. J. Linton, and L. M. Bradley, "CD44 regulates survival and memory development in Th1 cells," Immunity, vol. 32, no. 1, pp. 104$115,2010$.

[7] T. J. Chapman, M. R. Castrucci, R. C. Padrick, L. M. Bradley, and D. J. Topham, "Antigen-specific and non-specific CD4+ T cell recruitment and proliferation during influenza infection," Virology, vol. 340, no. 2, pp. 296-306, 2005.

[8] M. Coccoris, E. Swart, M. A. de Witte et al., "Long-term functionality of TCR-transduced T cells in vivo," Journal of Immunology, vol. 180, no. 10, pp. 6536-6543, 2008.

[9] C. H. GeurtsvanKessel, M. A. M. Willart, L. S. van Rijt et al., "Clearance of influenza virus from the lung depends on migratory langerin $+\mathrm{CD} 11 \mathrm{~b}$ - but not plasmacytoid dendritic cells," Journal of Experimental Medicine, vol. 205, no. 7, pp. 1621-1634, 2008.

[10] K. M. Grebe, H. D. Hickman, K. R. Irvine, K. Takeda, J. R. Bennink, and J. W. Yewdell, "Sympathetic nervous system control of anti-influenza CD8+ T cell responses," Proceedings of the National Academy of Sciences of the United States of America, vol. 106, no. 13, pp. 5300-5305, 2009.

[11] M. R. Jenkins, R. Webby, P. C. Doherty, and S. J. Turner, "Addition of a prominent epitope affects influenza A virusspecific CD8+ T cell immunodominance hierarchies when antigen is limiting," Journal of Immunology, vol. 177, no. 5, pp. 2917-2925, 2006.

[12] D. J. Topham, M. R. Castrucci, F. S. Wingo, G. T. Belz, and P. C. Doherty, "The role of antigen in the localization of naive, acutely activated, and memory CD8+ T cells to the lung during influenza pneumonia," Journal of Immunology, vol. 167, no. 12, pp. 6983-6990, 2001.

[13] T. Hatziioannou, E. Delahaye, F. Martin, S. J. Russell, and F. L. Cosset, "Retroviral display of functional binding domains fused to the amino terminus of influenza hemagglutinin," Human Gene Therapy, vol. 10, no. 9, pp. 1533-1544, 1999.

[14] Z. N. Li, S. N. Mueller, L. Ye et al., "Chimeric influenza virus hemagglutinin proteins containing large domains of the Bacillus anthracis protective antigen: protein characterization, incorporation into infectious influenza viruses, and antigenicity," Journal of Virology, vol. 79, no. 15, pp. 10003-10012, 2005.

[15] W. A. Langley, K. C. Bradley, Z. N. Li, M. E. Smith, M. J. Schnell, and D. A. Steinhauer, "Induction of neutralizing 
antibody responses to anthrax protective antigen by using influenza virus vectors: implications for disparate immune system priming pathways," Journal of Virology, vol. 84, no. 16, pp. 8300-8307, 2010.

[16] G. Neumann, T. Watanabe, H. Ito et al., "Generation of influenza A viruses entirely from cloned cDNAs," Proceedings of the National Academy of Sciences of the United States of America, vol. 96, no. 16, pp. 9345-9350, 1999.

[17] A. Bender, L. K. Bui, M. A. V. Feldman, M. Larsson, and N. Bhardwaj, "Inactivated influenza virus, when presented on dendritic cells, elicits human CD8+ cytolytic T cell responses," Journal of Experimental Medicine, vol. 182, no. 6, pp. 16631671, 1995.

[18] P. Bilsel, M. R. Castrucci, and Y. Kawaoka, "Mutations in the cytoplasmic tail of influenza A virus neuraminidase affect incorporation into virions," Journal of Virology, vol. 67, no. 11, pp. 6762-6767, 1993.

[19] M. Li, G. M. Davey, R. M. Sutherland et al., "Cell-associated ovalbumin is cross-presented much more efficiently than soluble ovalbumin in vivo," Journal of Immunology, vol. 166, no. 10, pp. 6099-6103, 2001.

[20] S. Mandl, L. J. Sigal, K. L. Rock, and R. Andino, "Poliovirus vaccine vectors elicit antigen-specific cytotoxic $T$ cells and protect mice against lethal challenge with malignant melanoma cells expressing a model antigen," Proceedings of the National Academy of Sciences of the United States of America, vol. 95, no. 14, pp. 8216-8221, 1998.

[21] A. McAllister, A. E. Arbetman, S. Mandl, C. Pena-Rossi, and R. Andino, "Recombinant yellow fever viruses are effective therapeutic vaccines for treatment of murine experimental solid tumors and pulmonary metastases," Journal of Virology, vol. 74, no. 19, pp. 9197-9205, 2000.

[22] N. P. Restifo, D. R. Surman, H. Zheng, P. Palese, S. A. Rosenberg, and A. García-Sastre, "Transfectant influenza A viruses are effective recombinant immunogens in the treatment of experimental cancer," Virology, vol. 249, no. 1, pp. 89-97, 1998.

[23] H. Zheng, P. Palese, and A. García-Sastre, "Antitumor properties of influenza virus vectors," Cancer Research, vol. 60, no. 24, pp. 6972-6976, 2000.

[24] C. Moser, M. Amacker, A. R. Kammer, S. Rasi, N. Westerfeld, and R. Zurbriggen, "Influenza virosomes as a combined vaccine carrier and adjuvant system for prophylactic and therapeutic immunizations," Expert Review of Vaccines, vol. 6, no. 5, pp. 711-721, 2007.

[25] I. Marigo, L. Dolcetti, P. Serafini, P. Zanovello, and V. Bronte, "Tumor-induced tolerance and immune suppression by myeloid derived suppressor cells," Immunological Reviews, vol. 222, no. 1, pp. 162-179, 2008.

[26] M. W. L. Teng, J. B. Swann, C. M. Koebel, R. D. Schreiber, and M. J. Smyth, "Immune-mediated dormancy: an equilibrium with cancer," Journal of Leukocyte Biology, vol. 84, no. 4, pp. 988-993, 2008. 


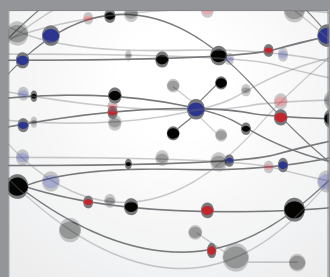

The Scientific World Journal
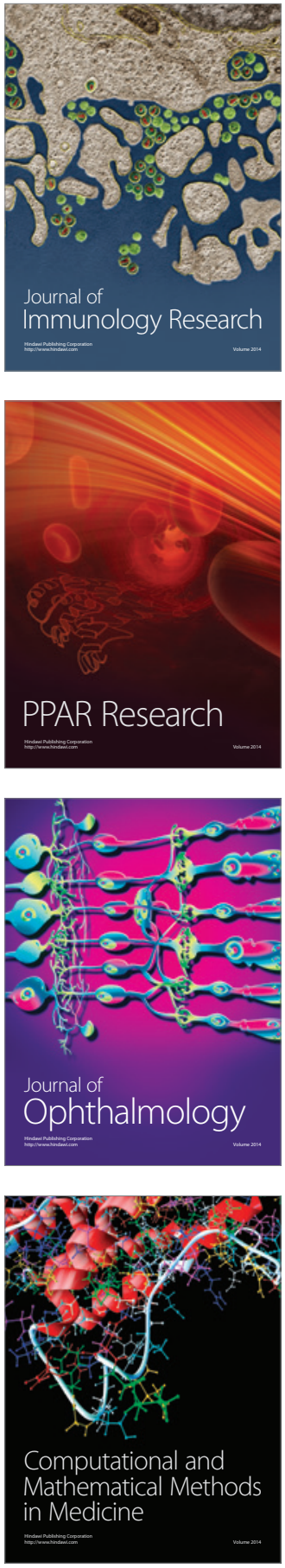

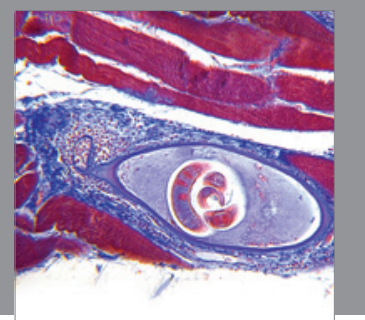

Gastroenterology

Research and Practice
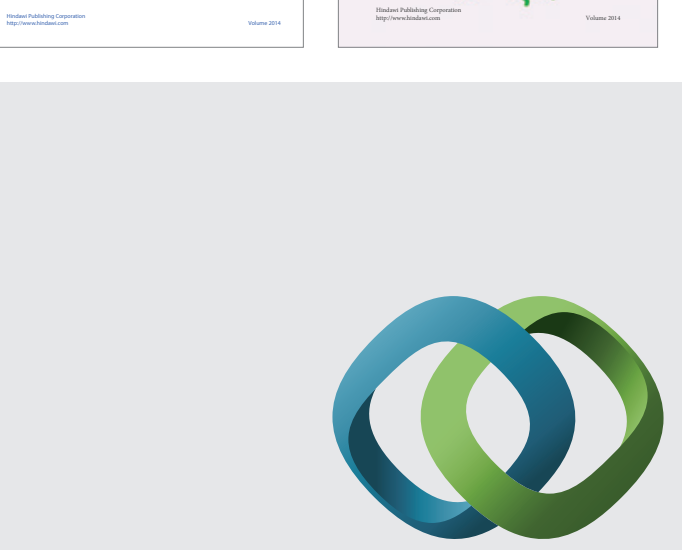

\section{Hindawi}

Submit your manuscripts at

http://www.hindawi.com
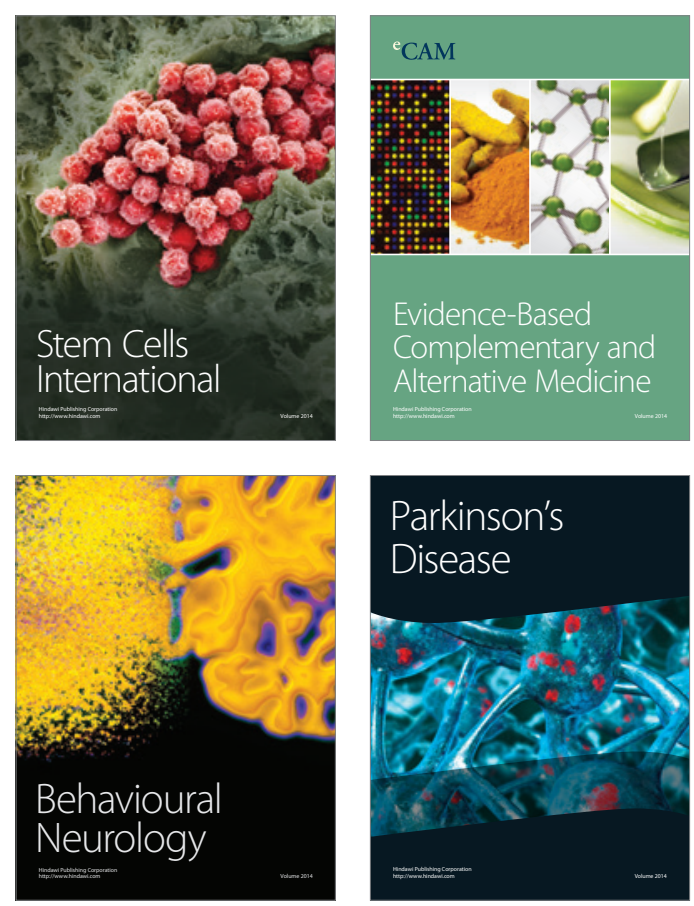

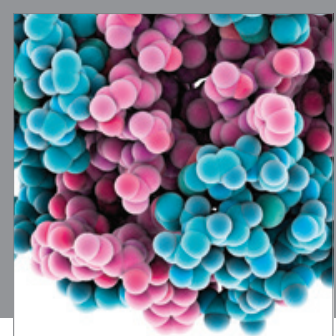

Journal of
Diabetes Research

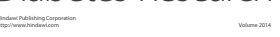

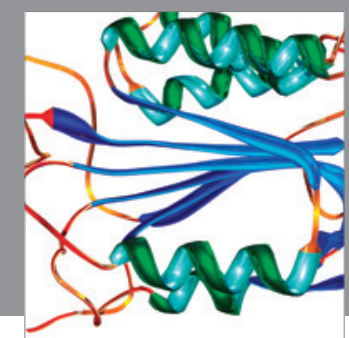

Disease Markers
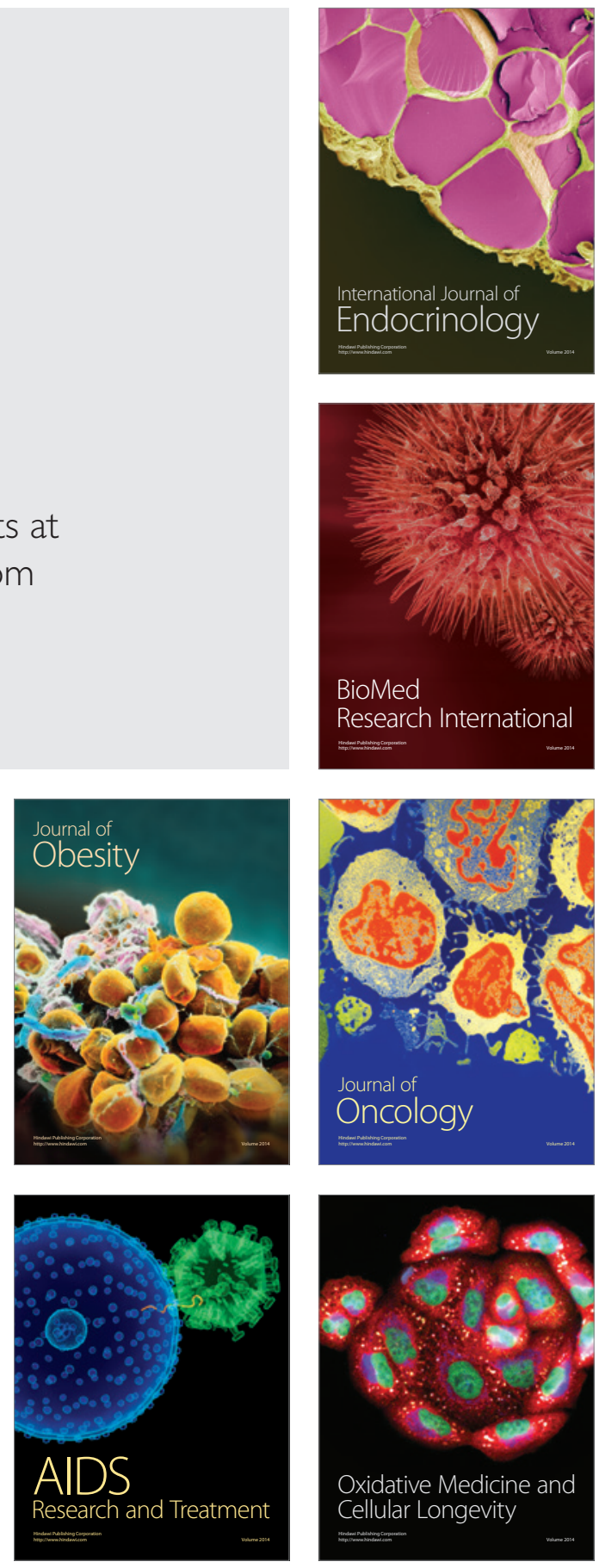